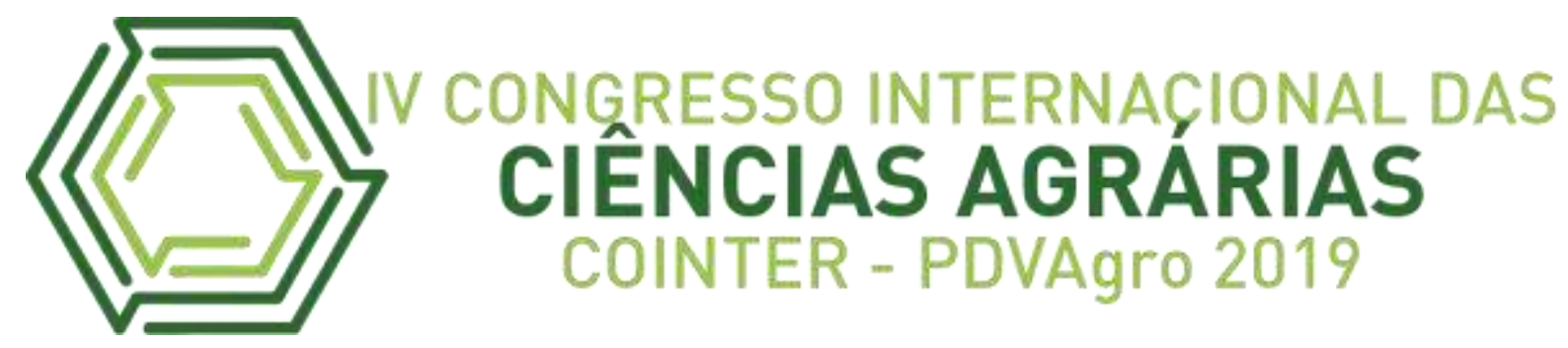

\title{
PERFIL DE CONSUMO DE LEITE E DERIVADOS POR ESTUDANTES UNIVERSITÁRIOS
}

\section{PERFIL DE CONSUMO DE LECHE Y DERIVADOS DE ESTUDIANTES UNIVERSITARIOS}

\section{PROFILE OF MILK CONSUMPTION AND DERIVATIVES BY UNIVERSITY STUDENTS}

\author{
Apresentação: Comunicação Oral
}

\begin{abstract}
Jéssyca Karolina de Lima Santos ${ }^{1}$; Krause Gonçalves Silveira Albuquerque ${ }^{2}$; Jefferson
\end{abstract} Renan Pinheiro Rodrigues ${ }^{3}$; Adjair José da Silva ${ }^{4}$

DOI: https://doi.org/10.31692/2526-7701.IVCOINTERPDVAgro.2019.0190

\section{Resumo}

É sabido que os hábitos alimentares, que tem seu início na infância e seguem seu percurso na vida adulta, onde alcançam seu ápice, sofrem modificações por diversos motivos, um deles e que é o embase desse trabalho, é a inserção do acadêmico na universidade, isso ocorre devido às mudanças sofridas no cotidiano desse indivíduo. O leite é um dos principais alimentos consumidos pela humanidade. Possui elevado destaque devido seu grande aporte nutricional, com destaque para as grandes quantidades de proteínas de alto valor biológico, carboidrato, ácidos graxos, sais minerais, vitaminas e água. Apesar de suas vantagens, muitas vezes os produtos lácteos não têm a devida consideração para consumo, seja por falta de informação ou por ausência na inserção na dieta diária. O objetivo deste trabalho foi avaliar a percepção dos consumidores (acadêmicos) a respeito das suas escolhas quanto aos tipos de leite e as opções de seus derivados. Para tanto, foram selecionados 450 estudantes universitários, voluntários, provenientes de diferentes instituições de ensino e apresentando idade e sexo variados, oriundos de diferentes cidades do estado de Pernambuco. Foi aplicado um questionário

\footnotetext{
Graduanda Engenharia de Alimentos, UFRPE - UAG, jessycakarolinals@gmail.com Graduando Engenharia de Alimentos, UFRPE - UAG, albuquerque.k.g.s@ gmail.com Graduando Engenharia de Alimentos, UFRPE - UAG, renan.jefferson2012@ gmail.com Eng. Agrônomo, IFPE, adjairsilva.agronomia.ifpe@gmail.com
} 
contendo perguntas relacionadas às suas características quanto indivíduo e ao consumo de leite e derivados. Os resultados evidenciaram que $77,1 \%$ dos acadêmicos declararam que optam pelo consumo de lácteos por apreciar o sabor destes produtos, 31,6\% por motivos de saúde, $29,6 \%$ por seu valor nutricional e $4,7 \%$ pelo preço. 43,8\% desses participantes consomem leite cru, enquanto $56,2 \%$ afirmam não consumir. O produto lácteo mais consumido foi o queijo $24,6 \%$ e o leite mais consumido foi o leite em pó integral $36,7 \%$. O resultado desse estudo destaca a necessidade de discutir esse tema durante a formação dos universitários e a importância de introduzir esses produtos na dieta diária, visando uma melhor qualidade de vida.

Palavras-Chave: Consumo de leite, Universitários, Questionário, Derivados do leite.

\section{Resumen}

Es bien sabido que los hábitos alimenticios, cuál es su inicio en la infancia y su curso en la edad adulta, donde alcanza su punto álgido, utilizan cambios por varias razones, una de ellas y cuál es este tipo de trabajo, es una inserción actividad académica en la universidad, esto se debe a cambios en la vida diaria de este individuo. La leche es uno de los principales alimentos que consume la humanidad. Tiene gran importancia debido a su gran número nutricional, destacando grandes cantidades de proteínas de alto valor biológico, carbohidratos, ácidos grasos, minerales, vitaminas y agua. A pesar de sus ventajas, los productos a menudo no se consideran debido al consumo, ya sea por falta de información o falta de inclusión en la dieta diaria. El objetivo de este trabajo fue evaluar la percepción de los consumidores (académicos) sobre el respeto de sus elecciones con respecto a los tipos de leche y las opciones de sus derivados. Para este propósito, se seleccionaron 450 estudiantes universitarios, voluntarios, participantes de diferentes instituciones educativas y de diferentes edades y sexos, de diferentes ciudades del estado de Pernambuco. Se aplicó un cuestionario que contenía preguntas relacionadas con sus características y consumo de leche y productos lácteos. Los resultados muestran que el $77.1 \%$ de los académicos afirman que eligen consumir alcohol porque disfrutan el sabor de los productos, el $31.6 \%$ por razones de salud, el $29.6 \%$ por su valor nutricional y el $4.7 \%$ por el precio. El $43,8 \%$ de estos participantes consume leche cruda, mientras que el $56,2 \%$ dice que no consume. El producto lácteo más consumido 
fue el queso $24.6 \%$ y la leche más consumida fue $36.7 \%$ de leche entera en polvo. El resultado de este estudio incluye la necesidad de discutir este tema durante la educación universitaria y la importancia de aplicar estos productos a la dieta diaria, utilizando una mejor calidad de vida.

Palabras Clave: Consumo de leche, estudiantes universitarios, cuestionario, derivados de la leche.

\begin{abstract}
It is well known that eating habits, what is their onset in childhood and following its course in adulthood, where it reaches its apex, uses changes for several reasons, one of them and what is this type of work, is an insertion academic activity at the university, this is due to changes in the daily life of this individual. Milk is one of the main foods consumed by mankind. It has high prominence due to its great nutritional number, highlighting large amounts of proteins of high biological value, carbohydrates, fatty acids, minerals, vitamins and water. Despite their advantages, products are often not considered due to consumption, either due to lack of information or lack of insertion in the daily diet. The objective of this paper was to evaluate the perception of consumers (academics) about the respect of their choices regarding the types of milk and the options of their derivatives. For this purpose, 450 university students, volunteers, participants from different educational institutions and of different age and sex, from different cities of the state of Pernambuco, were selected. A questionnaire containing questions related to its characteristics and consumption of milk and dairy products was applied. The results show that $77.1 \%$ of academics state that they choose to consume alcohol because they enjoy the taste of products, $31.6 \%$ for health reasons, $29.6 \%$ for their nutritional value and $4.7 \%$ for price. $43.8 \%$ of these participants consume raw milk, while $56.2 \%$ say they do not consume. The most consumed dairy product was cheese $24.6 \%$ and the most consumed milk was $36.7 \%$ whole milk powder. The result of this study includes the need to discuss this topic during college education and the importance of applying these products to the daily diet, using a better quality of life.
\end{abstract}

Keywords: Milk Consumption, College Students, Questionnaire, Milk Derivatives. 


\section{Introdução}

Todos os dias, bilhões de pessoas consomem leite no mundo, nas suas mais diversas formas. (SIQUEIRA, 2019b). Seu consumo ocorre estando ele ainda cru ou processado e transformado em produtos lácteos. O leite e seus derivados constituem um grupos de alimentos de grande aporte nutricional. De acordo com Visioli (2014), este alimento, apesar da intolerância que se verifica à lactose em alguns segmentos da população, se tornou um componente relevante na dieta de aproximadamente 6 bilhões de pessoas em todo o mundo.

Segundo a diretoria de pesquisas do Instituto Brasileiro de Geografia e Estatística IBGE (2018), em 2017 o Brasil apresentou-se como $6^{\circ}$ colocado dentre os maiores produtores de leite do mundo, a produção neste ano foi de 33,49 bilhões de litros. A Região Sul respondeu por $35,7 \%$ do total nacional mantendo a liderança do ranking, enquanto que a Região Sudeste, na segunda posição, representou $34,2 \%$ da produção total.

De acordo com Aquino et al. (2015) as mudanças ocorridas no perfil nutricional da população mundial, mediante influências de marketing de mercado e a demasiada celeridade do dia a dia em trabalho ou universidade ou ainda a mesclagem desses dois fatores, têm mudado os hábitos alimentares, principalmente dos jovens, que em sua grande maioria são universitários.

A alimentação cotidiana de estudantes universitários é alvo de muitos estudos que buscam avaliar os hábitos alimentares destes indivíduos e promover sugestões para uma melhoria. Vieira (2002) observou que em sua maioria, a alimentação do referido grupo tem baixa prevalência de alimentação saudável, com elevada ingestão de alimentos doces e gordurosos e baixa ingestão de frutas e hortaliças. Mattos et al. (2000) associam esta má alimentação à saída da casa dos pais, menor tempo para as refeições, localização da instituição, a trocas de refeições completas por lanches práticos e rápidos e o estabelecimento de novos comportamentos e relações sociais. Greaney et al. (2009) apontaram que o maior ganho de peso ocorre durante o início da fase adulta, ou seja aos 20 anos de idade e que, se caso esse ganho seja excessivo, pode aumentar a probabilidade de um indivíduo ter sobrepeso ou vir a tornar-se obeso em períodos posteriores da vida adulta. Os hábitos alimentares na fase acadêmica se apresentam como fator primordial para a melhora da qualidade de vida dos indivíduos (AQUINO; PEREIRA; REIS, 2015, p. 83). 
Segundo Siqueira (2018), a estimativa é de que o consumo de leite per capita no Brasil em 2017 foi de 173 litros/habitante. Em comparação com países desenvolvidos este consumo é baixo, tendo em vista que os indicadores variam entre 250 - 300 litros nestes países. É sabido que o leite é um produto que apresenta um rico aporte nutricional, mediante a este fato, a inserção deste alimento bem como de seus derivados na dieta diária, poderá contribuir para a compreensão e adequação de uma alimentação saudável, se abordado com maior clareza.

Nesse sentido e com a alta demanda do consumo do leite e de seus derivados, surge a necessidade de promover estudos, a fim de investigar quais os comportamentos dos consumidores (acadêmicos), no que diz respeito às suas escolhas quanto aos tipos de leite e as opções de seus derivados. Logo, esta pesquisa constrói-se como o objetivo de caracterizar e analisar os hábitos de estudantes universitários no que tange as questões relacionadas ao consumo de leite e seus derivados.

\section{Fundamentação Teórica}

O leite é um alimento de origem biológica, com sabor suave e próprio, agradável e ligeiramente adocicado, largamente consumido pela população e de alto valor nutritivo, pois contém grande quantidade de proteínas de alto valor biológico, carboidrato, ácidos graxos, sais minerais, vitaminas e água (GOULART et al., 2003; GARRIDO et al., 2001; SILVA et al., 2008). Segundo o Art. 475 do Regulamento de Inspeção Industrial e Sanitária de Produtos de Origem Animal (RIISPOA), entende-se por leite, sem outra especificação, o produto oriundo da ordenha completa, ininterrupta, em condições de higiene, de vacas sadias, bem alimentadas e descansadas (BRASIL, 2008).

Em 2009, Alvin e Moraes (2009) apontaram um crescimento considerável no mercado mundial de produtos lácteos, graças a ampliação do fluxo comercial, decorrente do processo de liberalização dos mercados, do aumento da renda per capita da população e do desenvolvimento tecnológico na produção de laticínios. Este crescimento tende a se perdurar no anos seguintes, mesmo havendo enfrentado um grande abalo entre os anos de 2015 e 2016, devido a crise econômica enfrentada pelo país, expressa pela redução do PIB e consequentemente a diminuição da renda das famílias, o setor lácteo vem obtendo elevação em sua produção e consumo (ABVL, 2018). Estima-se que em 2025 o Brasil produzirá 47,5 milhões de toneladas de leite (VILELA, 2015). 
As recomendações do Ministério da Saúde para o consumo de leite, em seu estado líquido ou de derivados lácteos, variam de acordo com a idade dos indivíduos. A recomendação para crianças de até dez anos é de $400 \mathrm{ml} /$ dia, isto é, 146 litros/ano de leite fluido ou equivalente na forma de derivados. Para os jovens de 11 a 19 anos, o consumo é maior, de $700 \mathrm{ml} /$ dia ou 256 litros/ano e para os adultos acima de 20 anos a recomendação é de $600 \mathrm{ml} /$ dia ou 219 litros/ano, inclusive para os idosos (BRASIL, 2006).

A busca por alimentos saudáveis, por uma melhor qualidade de vida e por uma dieta mais adequada vem revelando ao cenário mundial um aumento no consumo de leite e derivados lácteos, ao lado de uma crescente preocupação com a qualidade desses alimentos (SILVA; SOUZA, 2006). De acordo com Muniz et al. (2013), o conhecimento da frequência e da distribuição da ingestão de leite e derivados pela população é indispensável para direcionar estratégias nacionais e locais de incentivo ao consumo desses alimentos.

\section{Metodologia}

A pesquisa foi desenvolvida a partir da participação de 450 estudantes universitários voluntários provenientes de diferentes instituições de ensino e apresentando idade e sexo variados, oriundos de diferentes cidades do estado de Pernambuco. Os voluntários foram submetidos a um questionário on line contendo perguntas relacionadas a primeiro momento as suas características quanto indivíduo (Idade, sexo, instituição origem e etc) e em um segundo momento questões abordando as particularidades relacionadas a tipo e motivo de consumo de leite e produtos lácteos. Posteriormente os dados obtidos foram analisados e tabulados em planilhas do software Microsoft Office Excel 2016.

\section{Resultados e Discussão}

No que diz respeito ao grupo de pessoas que participaram da pesquisa, suas idades variaram entre 15 e 50 anos, onde $87,1 \%$ apresentou idades entre 15 e 25 anos. Quanto ao sexo dos participantes, $60,9 \%$ eram mulheres, $38,4 \%$ homens e $0,7 \%$ preferiu não declarar seu sexo. No que refere-se às instituições de origem, 16\% são estudantes de instituições de ensino privadas e $84 \%$ pertencem a instituições públicas, $100 \%$ dos participantes são alunos de graduação.

Dentre os fatores relevantes dessa pesquisa, destacam-se os motivos que levam os acadêmicos ao consumo dos lácteos. Para justificar o consumo 77,1\% dos acadêmicos 
declararam que optam pelo consumo de lácteos por apreciar o sabor destes produtos, 31,6\% por motivos de saúde, 29,6\% por seu valor nutricional e 4,7\% pelo preço.

De acordo com Chaves et al (2016) em seu trabalho a respeito do comportamento de consumo e avaliação sensorial em uma pesquisa realizada pelo Centro Científico Conhecer, destacou que como principais motivos para consumo do leite são: gostarem da bebida $(39,7 \%)$, por fazer bem à saúde $(30,4 \%)$ e por hábito $(21,1 \%)$.

Ao serem questionados em relação ao consumo de leite cru, 43,8\% dos participantes mencionaram consumir, enquanto 56,2\% afirmam não possuir hábitos de consumo de leite desta forma (Gráfico 1). Em contrapartida ORNELLAS et al (2017) ao estudar a percepção de estudantes em relação a qualidade de leite destinado ao consumo humano identificou que $92 \%$ dos seus entrevistados consome leite cru.

Gráfico 1: Consumo de leite cru por estudantes universitários.

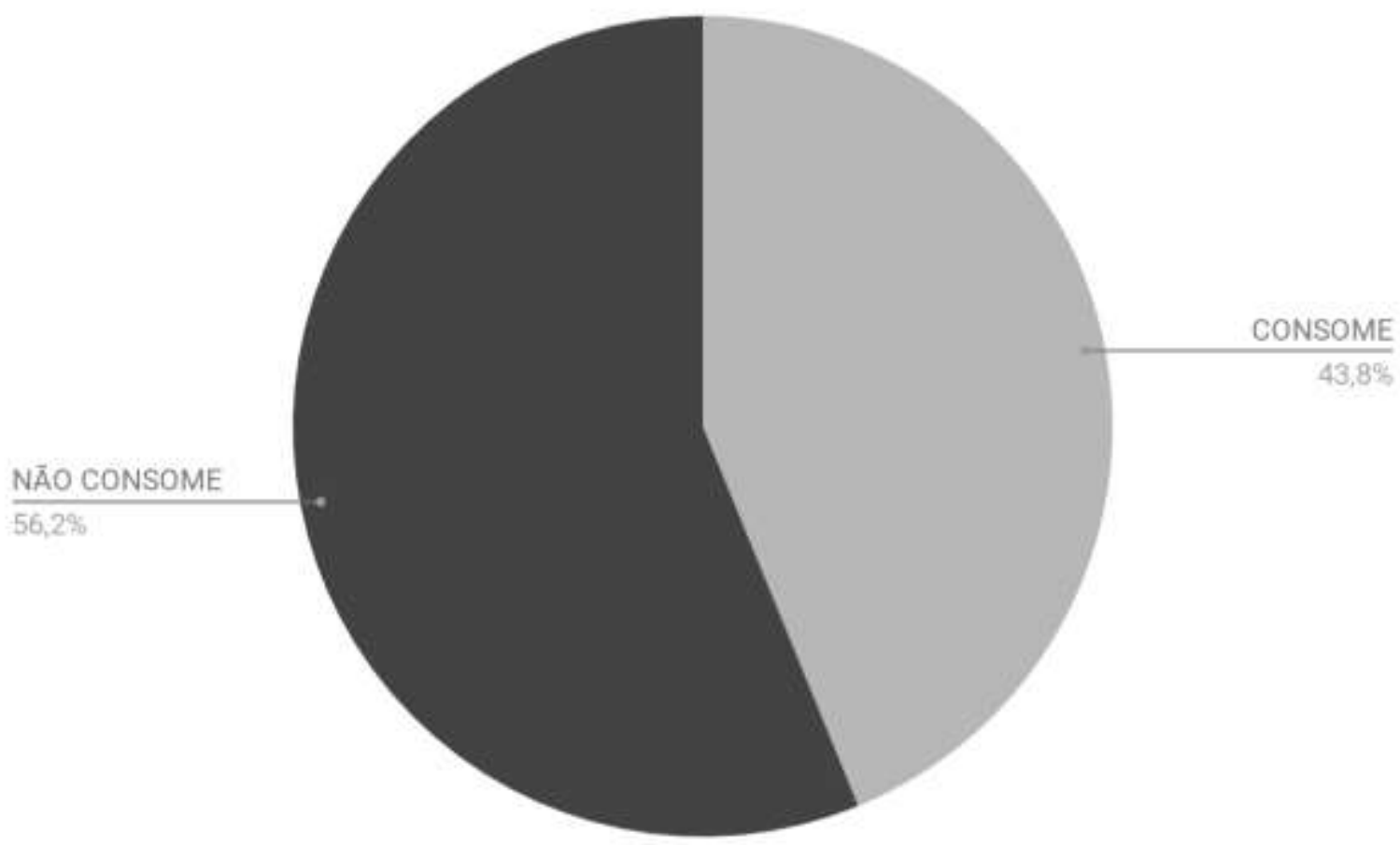

Fonte: Própria (2019)

O consumo de leite cru é um hábito presente em diversas regiões do país, sendo evidenciado como prática de pessoas do meio rural, onde muitas vezes há a presença de pequenas produções para consumo próprio, podendo ainda ser adquirido em supermercados, feiras livres e através de vendedores informais. Entretanto, como evidenciado por estudos, o consumo de leite in natura apresenta alta carga biológica e pode ainda conter 
microorganismos patogênicos e deteriorantes provenientes da variação do manejo sanitário dos animais e do processo de ordenha aplicados aos mesmos. Sovinski et al. (2014), em sua pesquisa registraram que $23 \%$ dos entrevistados eram consumidores de leite cru informal, além disso chamaram atenção para os riscos do consumo de leite informal tendo em vista que, ao analisarem 67 amostras demonstraram 97\% delas apresentaram inconformidades quando comparadas com as determinações que estão previstas na legislação nacional em vigor.

O gráfico 2 evidencia os locais frequentes onde os estudantes adquirem o leite cru, sendo o supermercado o local onde a maioria compra este produto, seguido da obtenção por intermédio de vendedores informais, gado próprio e feira livre.

Gráfico 2: Locais onde estudantes adquirem leite cru consumido.

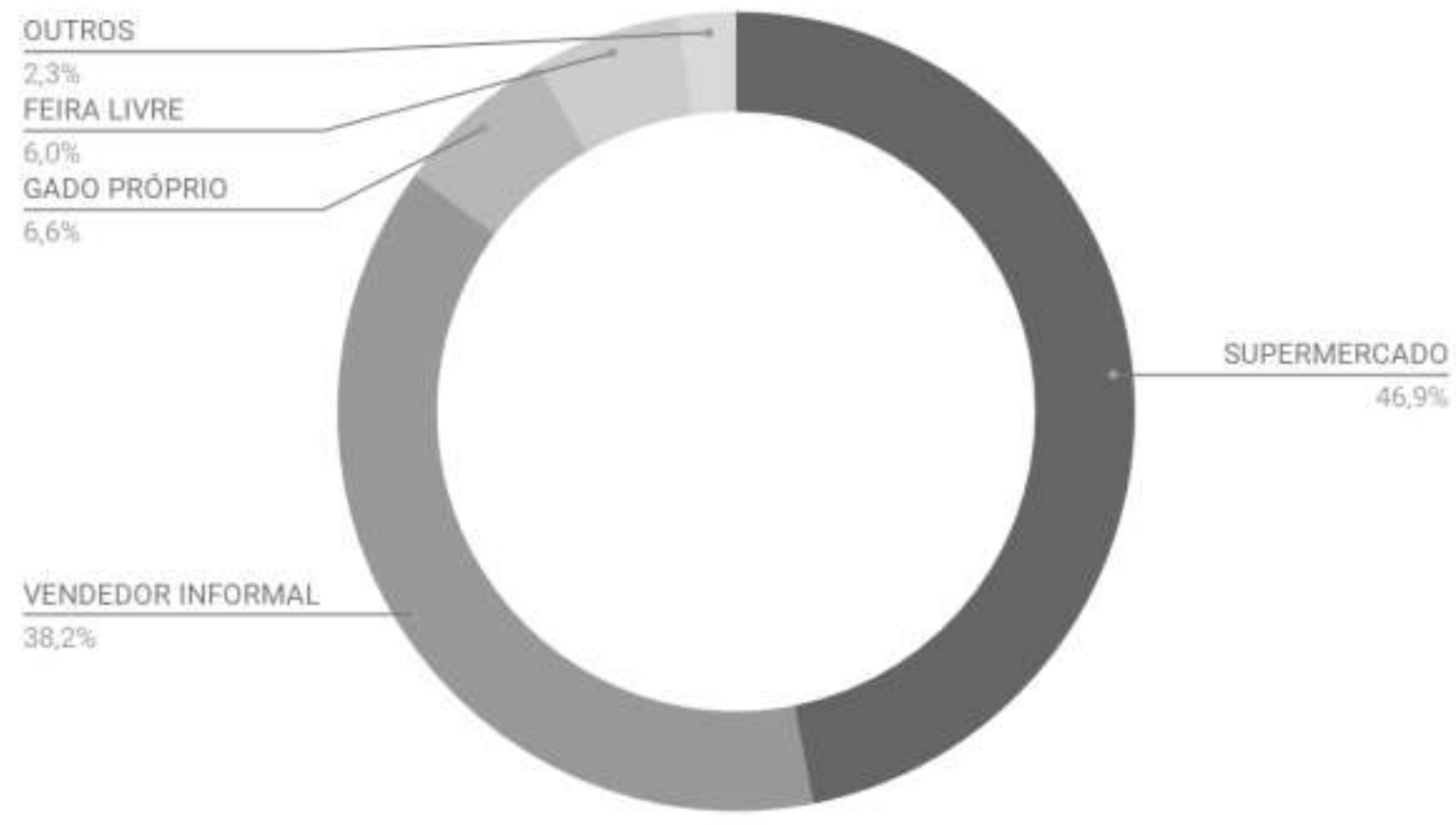

Fonte: Própria (2019)

Ao observar o consumo quanto aos tipos de leite por estes estudantes, pôde-se analisar que o leite em pó integral foi o mais consumido entre os 450 estudantes, obtendo um índice de $36,7 \%$, confirmando assim dados do relatório anual disponibilizado pela administração da Associação brasileira da Indústria de Lácteos Longa Vida - ABVL (2018), onde o leite em pó obteve um acréscimo de $45 \%$ quanto ao consumo. O leite que também merece destaque é o UHT integral que apresentou nesta pesquisa um percentual de $20,7 \%$.

O consumo de leite UHT, em 2017, atingiu um indicador de 7,025 bilhões de litros, 
194 milhões de litros a mais que 2016. O consumo do leite em pó foi de 3,050 bilhões de litros em 2017, 50 bilhões a mais que em 2016, crescimento explicado pela redução dos volumes importados. O consumo de leite pasteurizado também dispôs de expansão, havendo acrescimo de 1,4\% em 2017 quando comparado ao ano anterior. Enquanto que a bebida láctea foi o segmento de pior desempenho, com declínio de aproximadamente $12 \%$ de volume, com impacto ainda maior nos preços praticados pela categoria (ABVL, 2018).

Gráfico 3: Tipo de leite mais consumido por estudantes universitários.

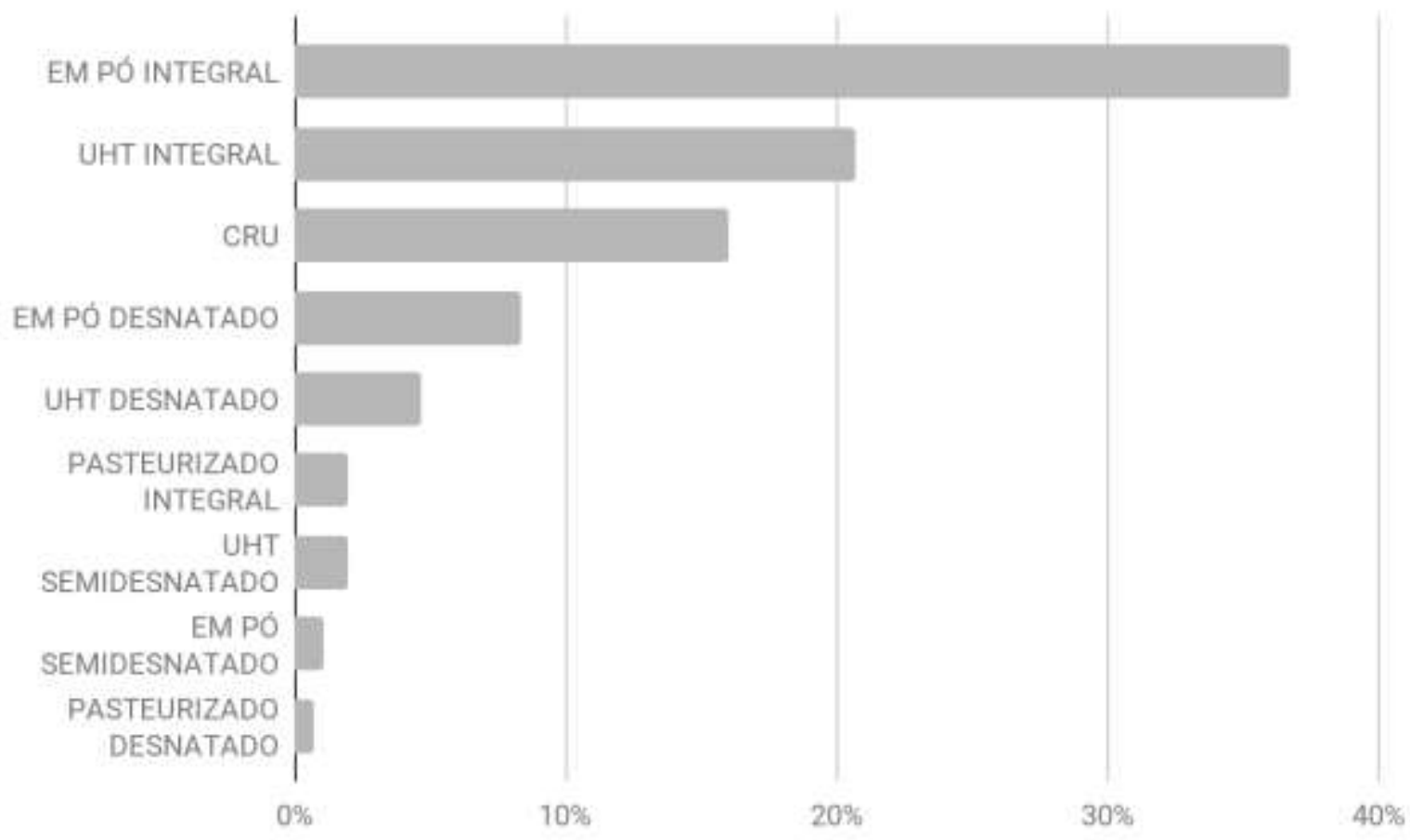

Fonte: Própria (2019)

Como demonstrado no gráfico 4, ao serem questionados se o leite industrializado é tão saudável quanto o in natura, em todas as faixas etárias a maioria dos estudantes respondeu que não. De forma análoga a opinião dos entrevistados, a FAO, em 2013 apontou que muitos consumidores optam pelo leite cru por acreditarem ser mais puro, natural e saudável que o leite industrializado. Porém, a prática de consumir o leite in natura, ou seja, sem tratamento térmico adequado, pode causar doenças de origem alimentar nos consumidores. Sendo este risco menor no leite industrializado, uma vez que este passa pela pasteurização.

ORNELLAS et al (2017) ao questionar seus consumidores sobre a preferência por leite industrializado ou não, identificou a mal percepção dos consumidores sobre o produto 
industrializado. Eles ressaltam a importância de criar diálogos entre as universidades e a sociedade no sentido de possibilitar espaços de formação a fim de que o consumidor possa identificar padrões de qualidade e tenha condições de cobrar dos produtores um mais alto padrão.

Gráfico 4: Opinião dos estudantes universitários, por idade, sobre a relação de saudabilidade entre o leite industrializado e in natura.

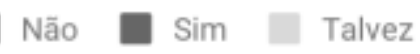

$80 \%$

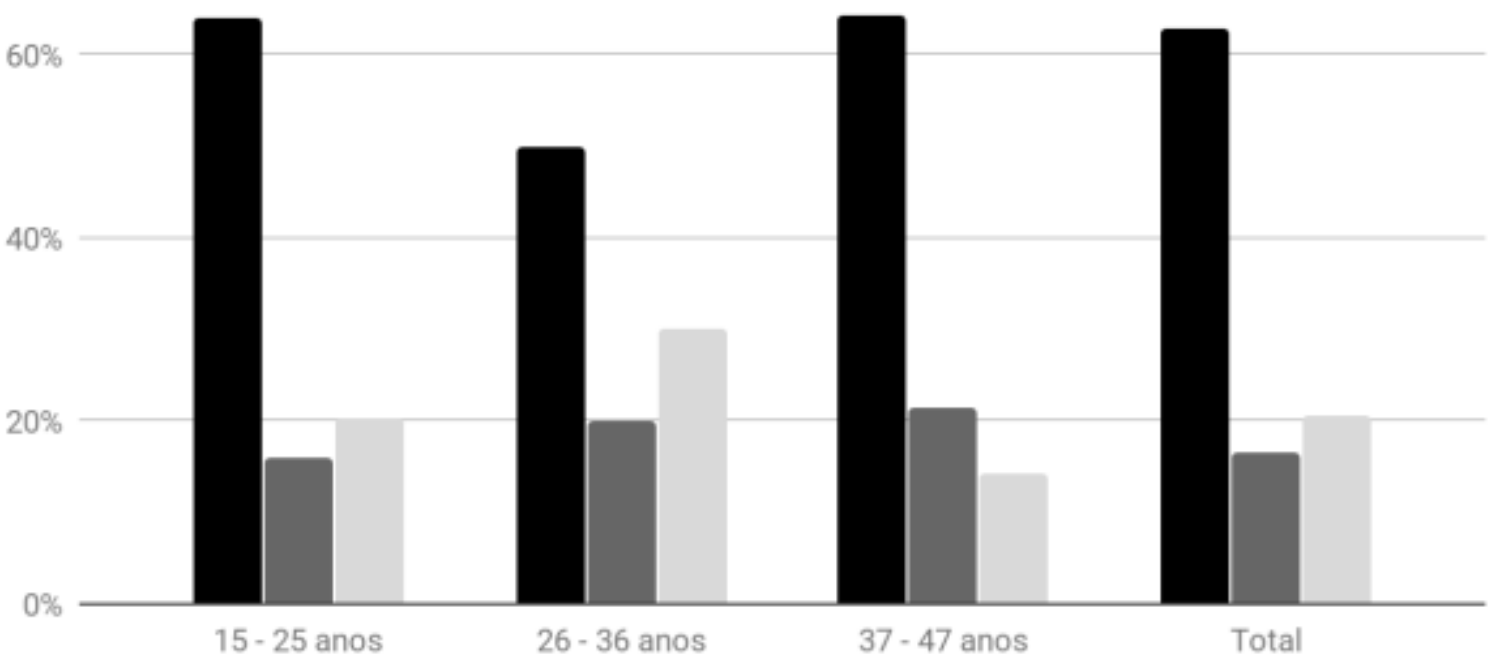

Fonte: Própria (2019)

O gráfico 5 representa os resultados obtidos na pesquisa quanto ao consumo de lácteos. O produto que se destacou em relação ao índice de consumo entre os estudantes universitários, cuja a maioria são jovens, foi o queijo, com 24,6\%. Siqueira (2019b) em sua pesquisa afirma que o queijo tem apresentado nos últimos anos crescimento nas taxas de vendas em consequência dos novos perfis de consumidores que buscam entre outros parâmetros por produtos nutritivos e práticos, sendo estes consumidores um público jovem, fator este que reafirma o dado supracitado que relaciona o consumo do produto em questão pelo público também destacado.

A manteiga, que muitas vezes é substituída pela margarina, por apresentar maior valor 
de mercado, dispôs de consumo elevado nesta pesquisa, apresentando $21,5 \%$ dentre os produtos mais consumidos. O consumo de iogurte também se sobressaiu, apresentando 20,2\% dentre os estudantes. Este derivado tem apresentado alta em seu consumo devido ao interesse da população por alimentos funcionais, ou seja, que tragam bons resultados à saúde intestinal. Os iogurtes são conhecidos por disporem de prebióticos, que auxiliam na regulação do intestino (SIQUEIRA, 2019a).

Outros produtos como bebidas lácteas $(17,1 \%)$ e doce de leite $(16,0 \%)$ também apresentaram resultados relevantes, outros derivados como requeijão, creme de leite e leite condensado tiveram menor índice de consumo. Pessoa et al (2018) encontrou em sua pesquisa dados semelhantes, apresentando entre as preferências dos consumidores em primeiro lugar o queijo, seguido de iogurte, manteiga, bebida láctea e requeijão.

Gráfico 5: Produtos lácteos mais consumidos entre estudantes universitários.

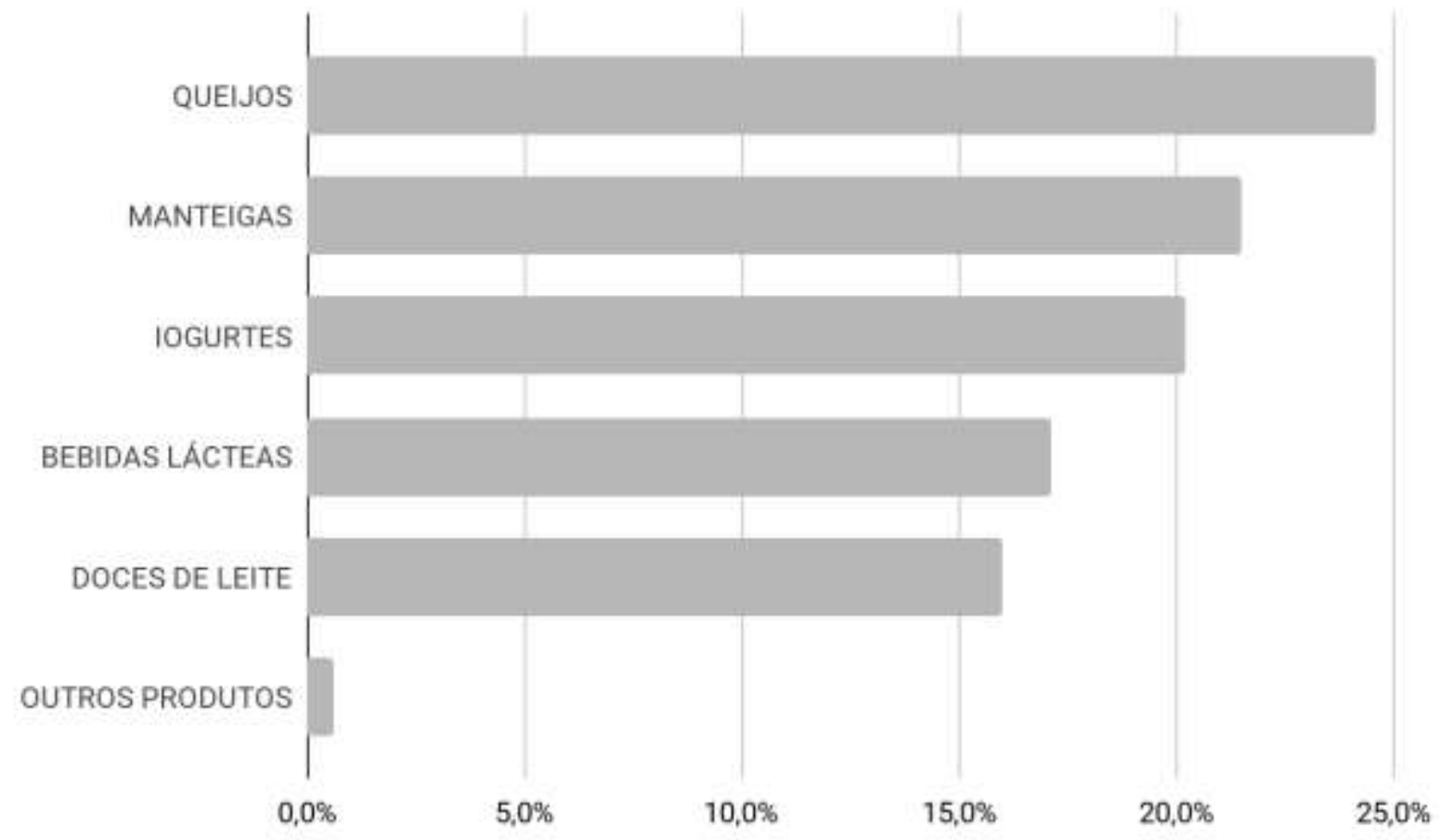

Fonte: Própria (2019)

Os estudantes que consomem queijo ainda foram questionados quanto ao tipo de queijo consumido. Uma pesquisa desenvolvida por Lencastre (2012) aponta os queijos mais produzidos no país, onde a mussarela apresenta $28 \%$, seguida do queijo prato com $19,9 \%$ e em terceiro o requeijão com $18,7 \%$ da produção. Entre os estudantes entrevistados houve 
divergência quanto a estes resultados, sendo o queijo coalho o mais consumido, dispondo de $55,8 \%$ da amostra e o mussarela em segundo lugar, com $34,7 \%$.

Gráfico 6: Tipos de queijos consumidos por estudantes universitários.

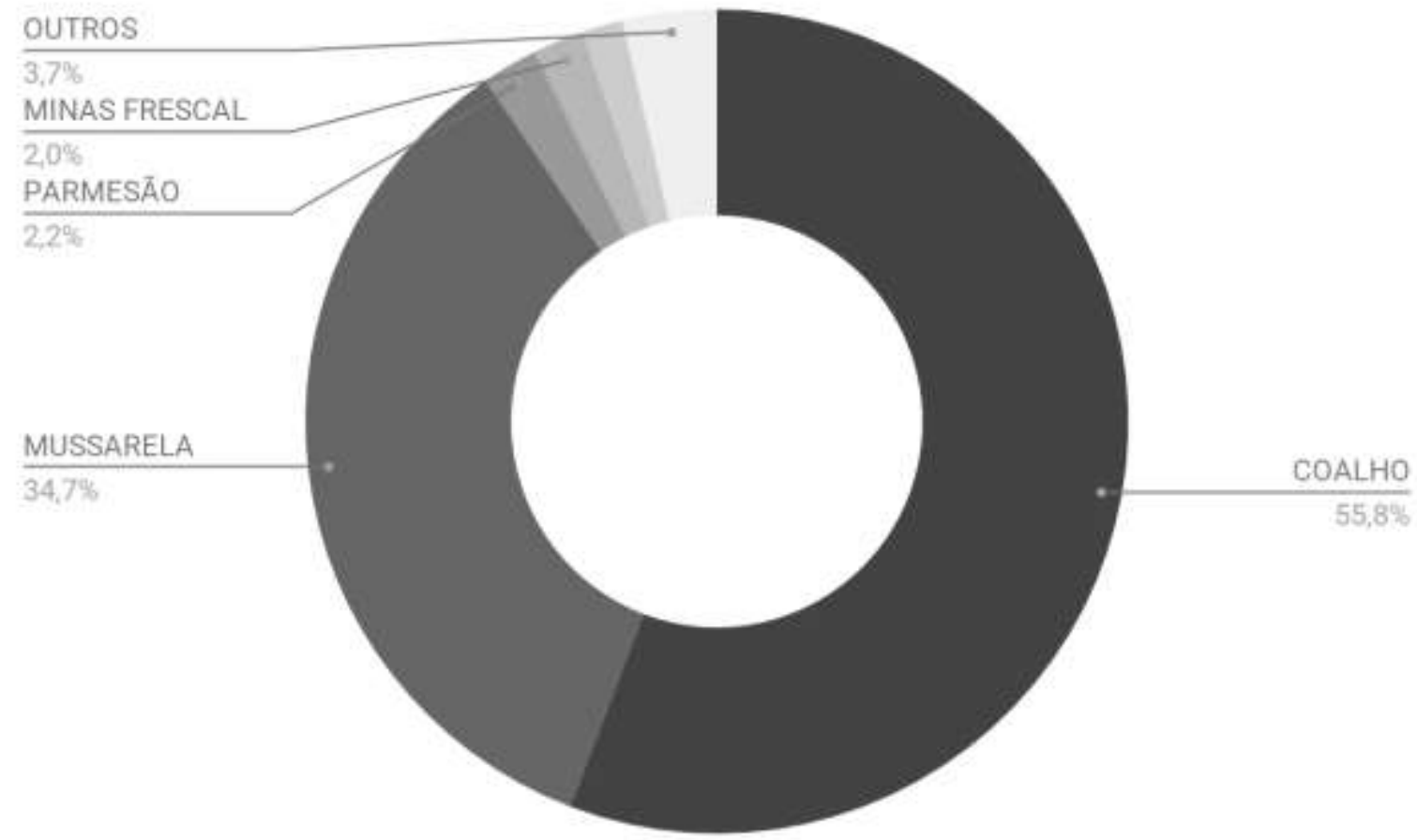

Fonte: Própria (2019)

\section{Conclusões}

Apesar de apresentar importância na alimentação do brasileiro, o leite ainda é um produto que não ocupa posição de destaque entre as bebidas mais consumidas. A pesquisa aplicada demonstra que boa parte da motivação que justifica o consumo do consumo do leite e/ou produtos lácteos está associada ao sabor, seguido das benesses para saúde. Ainda assim, vale destacar uma parcela considerável dos entrevistados acreditar que o leite industrializado é menos saudável que o leite in natura. Isso demonstra que, não há uma tendência por parte dos consumidores em buscar informações a respeito dos produtos que consomem, como acontece com o leite. $\mathrm{O}$ estudo também revelou que, o leite mais consumido pelos estudantes é o leite integral, bem como o produto lácteo mais consumido são os queijos. Isto mostra a importância de se conquistar o consumidor não somente pelo produto, mas com outros atributos associados à decisão de compra, como a praticidade e inovação de sabores. $\mathrm{O}$ resultado desse estudo destaca a necessidade de aprofundar cada vez mais o debate sobre esse 
tema durante a formação dos universitários e mostrar a importância de incorporar no seu cotidiano o aprendido sobre a introdução desses ricos produtos na dieta diária, visando uma melhor qualidade de vida.

\section{Referências}

ABVL. Relatório Anual 2017. 2017. 30 slides. Disponível em: <https://ablv.org.br/wpcontent/uploads/2018/09/ABLV-Relatorio-Anual-2017...pdf>. Acesso em: 30 ago. 2019.

ALVIN, A. M.; MORAES, S. L. O Mercado Internacional de produtos lácteos: Os efeitos do acordo Mercosul-UE sobre o Brasil. Economia e Tecnologia, v.17, p. 147 - 156, 2009.

AQUINO, J. K.; PEREIRA, P.; REIS, V. M. C. P. Hábito e Consumo Alimentar de Estudantes do Curso de Nutrição das Faculdades de Montes Claros - Minas Gerais. Revista Multitexto, 2015, v. 3, n. 01. p. 82-88.

BRASIL. Ministério da Saúde. Secretaria de Atenção à Saúde. Coordenação Geral da Política de Alimentação e Nutrição. Guia alimentar para a população brasileira: promovendo a alimentação saudável. Brasília, DF, 2006. p. 214.

BRASIL. Ministério da Saúde. Coordenação Geral da Política de Alimentação e Nutrição. Teste “Como está sua alimentação?”. Brasília, DF, 2008.

CHAVES, B. V.; LUCIA, S. M. D.; BOSI, M. G.; FILHO, T. G.; GONÇALVES, A. C. A. Mercado de Leite em uma Cidade de Pequeno Porte: Comportamento De Consumo E Avaliação Sensorial. In: ENCICLOPÉDIA BIOSFERA, Centro Científico Conhecer Goiânia, v.13 n.23; p.780, 2016.

FAO. Food and Agriculture Organization. Milk and dairy products in human nutrition. Rome; 2013.

GARRIDO, N. S.; MORAIS, J. M. T.; BRIGANTI ,R. C.; OLIVEIRA, M. A.; BERGAMINI, A. M. M.; OLIVEIRA, S. A. V.; FÁVARO, M. D. Avaliação da qualidade físico - química e microbiológica do leite pasteurizado proveniente de mini e micro - usinas de beneficiamento da região de Ribeirão Preto - SP. Revista do Instituto Adolfo Lutz, São Paulo, v. 60, n. 2, p. $141-146,2001$.

GOULART, S. M. Determinação de pesticida em leite pasteurizado. In: Congresso Nacional de Laticínios, 20., 2003. Juiz de Fora, MG. Anais... Juiz de Fora: Central Formulários, v. 28, n. 333, p. 39 - 44, 2003.

GREANEY, M. L.; LESS, F. D.; WHITE, A. A.; DAYTON, S. F.; RIEBE, D.; BLISSMER, 
B.; SHOFF, S.; WALSH, J. R.; GREENE, G. W. College students' barriers and enablers for healthful weight management: A qualitative study. J.Nutr. Educ. Behav, v. 41, p. 281-286, 2009.

IBGE. Pesquisa da Pecuária Municipal. 2018. 37 slides. Disponível em: $<$ https://agenciadenoticias.ibge.gov.br/media/com_mediaibge/arquivos/6d3123bbf5f78aa3492 c41003c7a38f6.pdf>. Acesso em: 30 ago. 2019.

LENCASTRE, K. G. S. Mapeamento da Produção de Soro de Queijo no Estado do Rio de Janeiro: Potencial para Produção de Etanol. Dissertação (Mestrado) - Universidade Federal do Rio de Janeiro, Escola de Química, Programa de Pós-Graduação em Tecnologia de Processos Químicos e Bioquímicos, Rio de Janeiro, 2012.

MATTOS, L. L.; MARTINS, I. S. Consumo de fibras alimentares em população adulta. Rev. Saúde Pública, São Paulo, v. 34, p. 50-55, 2000.

MUNIZ, L.C.; MADRUGA, S.W.; ARAUJO, C.L. Consumo de leite e derivados entre adultos e idosos no Sul do Brasil: um estudo de base populacional. Ciência saúde coletiva, vol.18, n.12, pp. 3515-3522, 2013.

ORNELLAS, T. S.; MONTEIRO, J. S. A.; NETO, J. N. S. M.; MORAIS, S. V. F.; PRÉ, L. S. L.; SILVA, R. C.; GOMES, F. F. Percepção de Estudantes Sobre a Produção e Qualidade do Leite Destinado ao Consumo Humano. SEAGRO: Anais da Semana Acadêmica do Curso de Agronomia do CCAE/UFES, 20., Alegres - ES, 2017.

PESSOA, R. M. S.; GOIS, G. C.; SILVA, A. A. F.; CAMPOS, F. S.; LIMA, C. A. B. Perfil dos consumidores de leite e derivados lácteos do município de Olho D’água - Paraíba. Nutritime Revista Eletrônica, on-line, Viçosa, v.15, n.02, p.8142-8146, mar./abr, 2018. ISSN: 1983-9006. Disponível em: https://www.nutritime.com.br/arquivos_internos/artigos/Artigo_464.pdf>. Acesso em: 19 outubro 2019.

SILVA, S.; SOUZA, C. Avaliação microbiológica de queijo tipo minas frescal comercializado na cidade de Belém - Pará. Belém: Laboratório Central do Estado do Pará; Centro Tecnológico da Universidade Federal do Pará, 2006.

SILVA, M. C. D.; SILVA, J. V. L.; RAMOS, A. C. S.; MELO, R. O.; OLIVEIRA, J. O. Caracterização microbiológica e físico - química de leite pasteurizado destinado ao programa de leite no Estado de Alagoas. Ciência e Tecnologia de Alimentos, Campinas, SP, v. 28, n. 1, p. 226 - 230, jan./mar. 2008 . 
SIQUEIRA, K. B. Leite e derivados: tendências de consumo. In: Embrapa Gado de Leite. Anuário Leite 2018. Castro-PR: Texto Comunicação Corporativa, p. 58-59, 2018.

SIQUEIRA, K. B. Leite e derivados: Novas tendências. In: Embrapa Gado de Leite. Anuário Leite 2019. Castro-PR: Texto Comunicação Corporativa, p. 74-75, 2019a.

SIQUEIRA, K. R. O Mercado Consumidor de Leite e Derivados. Circular Técnica. Embrapa Gado de Leite. Juiz de Fora, MG, julho, 2019b. Disponível em: $<$ https://www.infoteca.cnptia.embrapa.br/infoteca/bitstream/doc/1110792/1/CT120MercadoC onsumidorKennya.pdf>. Acesso em: 30 ago 2019.

VIEIRA, C. M.; SABADIN, E.; OLIVEIRA, M. R. M. Avaliação das práticas alimentares e do estado nutricional de universitárias do primeiro ano de nutrição. Rev. Simbio Logias, v. 1, n. 1, p. 87- 98, 2002.

VILELA, D. Para onde caminha o leite. Revista Balde Branco, n. 603, p. 41-43, jan. 2015. VISIOLI, F. \& STRATA, A. (2014). Milk dairy products, and their functional effects in humans: A narrativa review of recent evidence. Advances in Nutrition. Volume 5: pp. 131143. 